NBER WORKING PAPER SERIES

\title{
THE CONTROL OF POLITICIANS IN DIVIDED SOCIETIES: THE POLITICS OF FEAR
}

\author{
Gerard Padro i Miquel \\ Working Paper 12573 \\ http://www.nber.org/papers/w12573 \\ NATIONAL BUREAU OF ECONOMIC RESEARCH \\ 1050 Massachusetts Avenue \\ Cambridge, MA 02138 \\ October 2006
}

I wish to thank Daron Acemoglu, Abhijit Banerjee and Jim Snyder for encouragement and advice. I thank George-Marios Angeletos, Robert Bates, Kanchan Chandra, Jim Fearon, Drew Fudenberg and Ivan Werning for helpful conversations. For suggestions and comments I am grateful to Pol Antras, Raphael Auer, Sylvain Chassang, Erik Snowberg, Romain Wacziarg and several seminar participants at MIT, Harvard, Brown, Columbia, Yale, Stanford, NYU, Kellogg, UC Berkeley, Caltech, IIES, IAE, the NBER Summer Institute and the CIAR institutions meeting. All remaining errors are mine. I gratefully acknowledge financial support from the Fundacion Ramon Areces. The views expressed herein are those of the author(s) and do not necessarily reflect the views of the National Bureau of Economic Research.

(C) 2006 by Gerard Padro i Miquel. All rights reserved. Short sections of text, not to exceed two paragraphs, may be quoted without explicit permission provided that full credit, including $\bigcirc$ notice, is given to the source. 
The Control of Politicians in Divided Societies: The Politics of Fear

Gerard Padro i Miquel

NBER Working Paper No. 12573

October 2006

JEL No. D72,H2,O17,O55

\begin{abstract}
$\underline{\text { ABSTRACT }}$
Autocrats in many developing countries have extracted enormous personal rents from power. In addition, they have imposed inefficient policies including pervasive patronage spending. I present a model in which the presence of ethnic identities and the absence of institutionalized succession processes allow the ruler to elicit support from a sizeable share of the population despite large reductions in welfare. The fear of falling under an equally inefficient and venal ruler that favors another group is enough to discipline supporters. The model predicts extensive use of patronage, ethnic bias in taxation and spending patterns and unveils a new mechanism through which economic frictions translate into increased rent extraction by the leader. These predictions are consistent with the experiences of bad governance, ethnic bias, wasteful policies and kleptocracy in post-colonial Africa.

Gerard Padro i Miquel

Graduate School of Business

Stanford University

518 Memorial Way

Stanford, CA 94305-5015

and NBER

gpadro@stanford.edu
\end{abstract}




\section{Introduction}

Different strands of research have pointed to the importance of institutions as determinants of economic development. Political institutions influence policy determination by placing constraints on the behavior of leaders and inducing them to take into account the well-being of their citizens ${ }^{1}$. When institutions are weak, such as in most sub-Saharan post-colonial Africa, examples abound of rulers able to extract enormous rents from power in a seemingly unconstrained manner ${ }^{2}$. However, these rulers also engaged in extensive redistribution of resources in surprisingly inefficient ways, which suggests the existence of constraints on the exercise of power. Specifically, they often raised revenue through costly market manipulations and then spent on inoperant bureaucracies that served as distribution channels for patronage ${ }^{3}$. Such policies have taken a heavy toll on the performance of developing economies ${ }^{4}$. Surprisingly, in spite of their conspicuous wealth accumulation and their mismanagement of the economoy some of these leaders have received active support from sizeable shares of their impoverished populations. ${ }^{5}$ This raises the following questions: why do parts of the population support these leaders? Why do these leaders choose to engage in wasteful patronage transfers? Why are these leaders not accountable to their supporters?

To answer these questions, this paper develops a simple framework to analyze the

\footnotetext{
${ }^{1}$ The seminal theoretical work on these lines is Barro (1973) and Ferejohn (1986). In these models the politician is portrayed as an agent of a representative citizen. The leader can shirk to the extent that she enjoys some informational advantage, but the citizen places limits on this potential shirking by replacing the ruler when the outcomes are bad.

${ }^{2}$ See Ayittey (1992) or Mbaku (2000) for an account of the extent of rent extraction. For instance, several rulers such as Mobutu, Moi or Houphouet-Boigny have been estimated to posess personal fortunes equivalent to the total foreign debt accumulated by their countries.

${ }^{3}$ The use of monopsonistic Marketing Boards to extract resources from the agricultural sector (see Bates 1981), financial repression and foreign exchange rate manipulations have been some of the highly inefficient ways revenues have been raised.

${ }^{4}$ For the effect of bad policies in Africa, see Collier and Gunning (1999), Easterly and Levine (1997) and Easterly (2002). For the effect of political and bureaucratic inoperance see, for instance, Mbaku (2000).

${ }^{5}$ It is suprising to see many instances where large populations are easily mobilized by the regime: ethnic voting is such an example and is pervasive in the continent. This support can also include decentralized violence against the opposition such as in Rwanda in 1994 or in contemporary Zimbabwe. Note also that some of the presumed authoritarian leaders, such as Benin's Kérékou, have been reelected when multiparty elections have been introduced.
} 
political economy of this type of regimes. The starting point is a political agency model in which three assumptions are maintained:

1. A Ruler needs the support of his ethnic group in an ethnically divided society

2. Ruler replacement leads to political instability and increases the likelihood of a switch of power between ethnic groups

3. Taxation can only vary by economic activity while transfers can target groups directly

Assumption 1 captures the political salience of ethnicity in these societies. The second assumption formally captures an aspect of succession that is fundamental in understanding accountability when institutions are weak. These two assumptions imply a seemingly paradoxical result: the ruler can maintain support from his ethnic followers even though he is extracting resources from them. The reason is that in equilibrium, a leader steals resources from his supporter group, but extracts even more from the opposition group. If the group in power decides to keep their leader, the stability of the regime maintains the status quo. If they decide to oust him they face a chaotic succession process in which they cannot guarantee the next leader will belong to their group. Since their predicament under the leadership of a politician from another group is worse than under their own ethnic ruler, the latter can capture the support of his ethnic followers while reducing their utility. ${ }^{6}$ I call this fundamental mechanism the Politics of Fear: if succession is not fully controlled by supporters and they would be worse off under the opposition, leaders are not accountable to their own supporters.

Assumption 3 ensures that taxation rates across groups move in parallel in equilibrium. Since taxation can only be targeted to activities, agents can escape discriminatory taxation by switching activities. Hence, groups can only be discriminated by the taxing system to

\footnotetext{
${ }^{6}$ The opposition leader would like to promise to current supporters that he will not expropriate from them. However, such promises are not credible in this institutional environment.
} 
the extent that they do not perfectly arbitrage tax differences. ${ }^{7}$ Imperfect mobility across economic activities thus provides an upper bound to the difference in taxation that the ruler can levy, and the levels of taxation that groups suffer have to co-move in the same direction. With this assumption, two additional results can be derived.

First, the model shows that these fears of exclusion spread across groups and compound the ability of leaders to extract resources. Suppose group $A$ has a strong comparative advantage in a particular activity that leaves it vulnerable to expropriation. $A$ members thus know that a $B$ leader would expropriate them. Hence group $A$ 's leaders will be able to extract large rents from their $A$ supporters by virtue of the Politics of Fear. As noted above, when leader $A$ can tax his supporters heavily, he can also increase taxes on $B$ citizens. This implies that $B$ citizens also fear an $A$ leader that cannot be reigned in by his $A$ supporters. As a consequence, when a $B$ leader captures power, his group will allow him to steal; group $A$ 's fear of leadership change allows both $A$ and $B$ leaders to escape accountability. $^{8}$

I call this mechanism Amplification of Kleptocracy: the amount any group leader is able to divert is increasing in the fear of leadership change that any group feels. This mechanism is the general equilibrium counterpart of the Politics of Fear and is the force behind the comparative statics in this paper.

Second, the model provides a rationale for the inefficient use of public funds as resources for patronage to the ethnic kin of the leader. As discussed above, when the ruler wants to increase rent extraction, he needs to increase taxes in parallel for both groups. This is constrained by the need to provide his group with enough utility to keep its sup-

\footnotetext{
${ }^{7}$ Bureaucratic incapacity forces rulers to extract resources by manipulating markets because income taxes are not feasible. That there is stratification in economic activities across ethnic groups has long been noticed. In a classic study, Horowitz (1985) writes "Cementing the ethnic division of labor is the preeminent role of ascriptive ties in economic relations in the developing world". A comparative advantage in a particular activity implies that an increase of taxation is not met by an immediate withdrawal from that economic niche.

${ }^{8}$ The mechanism works for any policy dimension that creates a wedge between supporters and opposition. As section 4 shows, targeted ethnic violence or durable investment can be exploited in the same way.
} 
port. This constraint can be satisfied by redistributing targeted patronage to his group ${ }^{9}$. For every unit of patronage he supplies to his supporters, he can tax both his supporters (who are left indifferent) and his opponents. Hence only a fraction of the population (the supporting group) receives costly patronage in equilibrium but both groups suffer heavy taxation. As a consequence, patronage provides returns to the ruler that are higher than the social returns. This implies that patronage is provided to the point where the marginal return to the receiver is below the marginal social cost. When the leader has a small basis of support this distortion is exacerbated.

Therefore, this framework accounts for the existence of regimes in which weak leaders (in the sense that they need a sizeable share of the population to defend the regime) are able to extract enormous resources from the economy. This exploitation is achieved with the explicit support of the exploited which explains the failure of accountability observed in these countries. In addition, the framework is consistent with excess public employment, the presence of ethnic bias in the public office corps, regional bias in the targeting of expenditures and the coexistence of heavy rates of taxation and inefficient subsidization to supporter groups ${ }^{10}$. Moreover, the model shows how the economic ethnic segmentation present in Africa is consistent with the venality of its regimes in its postcolonial history.

Assumption 2 constitutes the main novelty of my approach. It is designed to capture a specific way in which institutions and politics in Africa and elsewhere have departed from the textbook representative democracy. When institutions are weak, the process of replacing a leader is not mediated by an established political institution, and lies beyond the control of the citizenry. Since rules of succession are not followed, the stability of the regime is contingent on the survival of the ruler. In their analysis of personal rule regimes, Jackson and Rosberg (1982) write "a succession [...] alters at least some of the important

\footnotetext{
${ }^{9}$ The role of ethnicity as an exclusion device is already present in Bates (1983) and Caselli and Coleman (2003). As opposed to taxation, patronage can easily be ethnically targeted by biasing the allocation of funds and bureaucratic posts and using ethnic identification as a discrimination device.

${ }^{10}$ As detailed in Bates (1981). Gavazza and Lizzeri (2005) address this phenomenon in a model where transfers are imperfectly observable.
} 
relationships and standings among leaders and factions - for example, the standing of big men and the clan and ethnic communities they represent" and "[t]he ultimate uncertainty in a system of personal rule lies in the key point of vulnerability: the ruler. [...] If he falls, his relatives, friends, lieutenants, clients and followers also may fall, and the ensuing political disruption may threaten the political peace." Hence, ousting a leader initiates an uncertain process that involves potential change in the relative status of different groups. The cases of Kenya in 1978 or Cameroon in 1982 are good examples of successions leading to dramatic switches in the standing of different ethnic groups. ${ }^{11}$

Acemoglu, Robinson and Verdier (2004) note that most qualitative analysts of weakly institutionalized regimes, often referred to as Personal Rule, Neopatrimonialism or Prebendalism, agree that in these countries, the arrangements described in the constitution with respect to due process, succession or legislative review of the executive are systematically ignored because the locus of power belongs to the person of the ruler and not to his office, and informalism prevails in every political transaction. ${ }^{12}$ In their formal analysis, Acemoglu et al. emphasize that weak institutions allow leaders to exacerbate the collective action problem of society. My approach abstracts from collective action problems and concentrates on the instability of succession rules, thereby unveiling a different mechanism. In addition to tackling the weakness of political accountability, my model explains why some exploited groups explicitly support kleptocratic leaders and also accounts for their inefficient provision of patronage.

This analysis is a contribution to the literature on the political economy of less developed polities. Acemoglu and Robinson (2001), Ellman and Wantchekon (2000), La Ferrara and Bates (2001), Robinson and Verdier (2005), and Robinson and Torvik (2002) present models of electoral competition enriched to capture diverse characteristics of the political

\footnotetext{
${ }^{11}$ At the death of Kenyatta in 1978, Daniel arap Moi reaches power. Kenyatta belonged to the Kikuyu ethnic group that dominated politics in Kenya since independence. After the transition, the balance of power dramatically moves to the Kalenjin group to which Moi belongs. A similar pattern can be found in the transition from Ahidjo to Biya in Cameroon and elsewhere in Africa. See for instance Mbaku (2000).

${ }^{12}$ See Bratton and van der Walle (1997), Jackson and Rosberg (1982), Migdal (1988) and Chabal and Daloz (1999) among many others. See also Herbst (2000) and Cooper (1999) for a discussion on the historical roots of this weak institutionalization.
} 
game in weakly institutionalized polities. In this literature, the presence of strong ethnic groups in society, the absence of institutional commitment technology or the capacity to resort to violence are introduced to explain inefficient policy choices and the presence of clientelism. My model shows that the insights of these previous papers keep their validity in a political accountability framework. Additionally, it explains why internal competition within the ruling group cannot dissipate kleptocratic rents.

It has already been suggested that distributional concerns among the citizenry could weaken accountability (see Ferejohn (1986)). In this work, different citizens compete to be included in the winning coalition of the ruler, thus bidding away all the rents. The nature of my mechanism is different: a ruler is tied to his group, but the prospect of future exclusion forces supporters to defend the regime and to keep the leader in power.

The remainder of the paper is organized as follows. The next section presents the model and the equilibrium concept that will be used. Section III analyzes the model, describes the equilibrium and contains a discussion on the interpretation of the model and its results, stressing the comparative statics. Section IV uses the logic of the model to examine the preponderance of wages over investment in Africa and the prevalence of ethnic violence. Finally, the last section concludes.

\section{The model}

\subsection{The Environment}

Consider an infinitely repeated economy populated by a continuum of citizens of mass 1 . Citizens belong to one of two ethnic groups, $A$ and $B$. The size of group $A$ is $\pi^{A}$. There are two economic activities, denoted $a$ and $b$. A group is defined by two distinct sets of characteristics. First, there are some ascriptive characteristics such as skin color (maybe geographical distribution or language) that are identifiable and, for simplicity, impossible to change. 
Second, each group possesses a comparative advantage in a different portfolio of economic activities. A group $A$ citizen obtains $\omega^{a}$ per period in activity $a$. Should she decide to take activity $b$ she would earn $\omega^{a}-\theta^{A}$ per period. Symmetrically, a $B$ citizen obtains $\omega^{b}$ in activity $b$ and $\omega^{b}-\theta^{B}$ in activity $a$, per period. $\theta^{i}$ captures the extent to which a group's wealth is specific to a particular activity. For example, if a citizen obtains her wealth from coffee, she can switch her efforts to growing rice in her fields. Unfortunately, coffee trees are a long term specific investment, and hence putting those lands to another use entails a loss of pre-tax income. In general, a group that is specialized in cash-crops, especially tree crops, has no way to transfer its planted capital to another activity. The same is true for groups that relie on ethnic networks to perform particular activities. On the other hand, $\theta^{i}$ may simply capture the degree to which specialized knowledge is useless in another sector. Finally, a small value of $\theta^{i}$ also captures the possibility that ethnic groups are not differentiated by economic activities. For simplicity, assume that switching is allowed each period. Let $z_{t}^{i}=1$ if group $i$ does not take the activity in which it enjoys comparative advantage in period $t$. Otherwise $z_{t}^{i}=0$.

There is a state that performs two functions: it taxes economic activities and uses the proceeds to provide benefits to groups.

These benefits might be public goods that are so dependent on taste that only one of the groups enjoys them. The favoured interpretation is that they constitute pure patronage such as the allocation of public resources to the region of a group or the granting of lucrative bureaucratic posts (or posts in the army, police, etc.) to members of the favored group. The state is able to discriminate across recipients of public expenditure thanks to the ascriptive characteristics of groups.

On the other hand, taxes are activity specific because in particularly poor developing countries as in Africa, the absence of a competent bureaucracy forces the governments to raise their revenue from indirect taxation. For instance, the use of Marketing Boards for agricultural products and other manipulations of the pricing system have been pervasive. ${ }^{13}$

\footnotetext{
${ }^{13}$ Bates (1981) provides a detailed account of these practices. In addition, Bates (1989) shows that
} 
In the context of the model, I allow taxation to differ across group-activities, but the ability to imperfectly switch activities will put a ceiling on how differently one can tax different sources of wealth. Thus note that the fundamental difference between expenditures and taxation is that patronage can be perfectly targeted to specific groups.

At any point in time, one ethnic group has control of the government. Even though a group has the state nominally captured, real power is exercised by a narrow elite inside the group, and I will call it the Leader. Denote by $L^{i}$ the leader if he is from group $i$. In the remainder of the paper, I call the group to which the leader belongs "supporter" group, and the other is denoted "excluded" group for reasons that will become apparent. Each group has an unlimited supply of identical leaders from which to choose.

Denote $\tau^{i k}$ the tax level that a leader of group $i$ levies on activity $k$. Similarly, let $\eta^{i j}$ be the amount that a leader of group $i$ spends on patronage for group $j$. Obviously $i, j \in\{A, B\}$ and $k \in\{a, b\}$. The amount $\eta^{i j}$ provides utility $R\left(\eta^{i j}\right)$ to group $j$ with $R^{\prime}>0, R^{\prime}(0)>1, R^{\prime \prime}<0$ and $R(0)=0$. Group $-j$ receives no utility from $\eta^{i j}$.

This economy has two fundamental states, $S_{t} \in\{A, B\}$, denoting whether power is captured by group $A$ or group $B$ in period $t$.

The instantaneous utility of a citizen of group $A$ in state $S$ (the expression for $B$ is symmetric) is thus:

$$
C\left(S, z^{A}\right)=\left(1-z^{A}\right)\left(\omega^{A}-\tau^{S a}\right)+z^{A}\left(\omega^{A}-\theta^{A}-\tau^{S b}\right)+R\left(\eta^{S A}\right)
$$

where time subscripts have been omitted for notational simplicity.

Both groups have identical preferences represented by $\mathbf{E} \sum_{t=0}^{\infty} \delta^{t} C_{t}^{j}$, where $C_{t}^{j}$ is the consumption of group $j$ at time $t$, and $\delta$ is the discount factor.

Even though the leader belongs to group $S_{t}$, he has self-serving interests. In particular, he wants to maximize the funds that he can divert for his own uses. A leader of group $A$ obtains instantaneous utility (the expression for $B$ is just symmetric) as long as he is in these manipulations are inefficient to the point of contributing to famines. 
power:

$U^{A}=\tau^{A a}\left(\pi^{A}\left(1-z^{A}\right)+\left(1-\pi^{A}\right) z^{B}\right)+\tau^{A b}\left(\pi^{A} z^{A}+\left(1-\pi^{A}\right)\left(1-z^{B}\right)\right)-\pi^{A} \eta^{A A}-\left(1-\pi^{A}\right) \eta^{A B}$

and discounts future payoffs by $\delta$. When a leader is not in power, he obtains 0 utility per period.

The weakness of institutions and the importance of ethnic links is captured in the model by the following assumptions. First, assume that whenever the incumbent leader retains the support of his kin group, he maintains his position with probability $\bar{\gamma}^{A}$. With probability $1-\bar{\gamma}^{A}$ group $B$ is able to dislodge the leader from power and install a $B$ leader even against a united $A$ group. $\bar{\gamma}^{A}$ might be well above $\pi^{A}$ to capture the notion that weakness of institutions and the strength of ethnic links allow for a huge degree of incumbency advantage. This is the sense in which a group might be able to capture power. The unique credible source of support and thus the unique credible promise of future patronage is given by the ruler's ethnic linkage with his own group ${ }^{14}$.

Second, if the supporters of an incumbent leader decide to subvert the authority of their leader and want to oust him from power, they succeed automatically, as a leader with no basis of support cannot survive. Hence the relevant constraint on the interests of the leader is the need to keep the support of his group. This is the sense in which the position of the leader is weak: he needs the active support of a sizeable share of the population to maintain power.

Third, when a leader is ousted from power by his own supporters the state does not perform its functions for that period. Moreover, the group that is not in power will find it easier to use this opportunity to grab power and seat a leader from its ranks. This

\footnotetext{
${ }^{14}$ The group has to feature two characteristics: firstly, it has to be very costly to change one's identity ex-post. Secondly, the ruler has to be able to commit to use the same basis of support in the future. The experience in Africa and elsewhere suggests that ethnic allegiances possess both features. Fearon and Laitin (1996), Bates (1983, 2000), Miguel and Gugerty (2005) or Fafchamps (2004) provide examples of social, economic and political arrangements in Africa that are possible because the existence of ethnic linkages permits commitment to socially established rules.
} 
captures the reality of Personal Rule regimes in which successions are always uncertain matters, resolved in non-institutionalized ways. Thus, I assume that the status of the group in power will change with probability $1-\underline{\gamma}^{S} \cdot \underline{\gamma}^{S}$ captures the degree to which the grip on power of group $S$ is solid independently of the personality of the ruler. In other words, $\bar{\gamma}^{S}-\underline{\gamma}^{S}>0$ captures the importance of "Personal Rule" since it measures the increased stability that retaining the incumbent buys to his supporters. In essence this assumption just means that stability is good to maintain power.

The timing of each stage game, given state $S_{t}$, is the following:

1. Leader $L^{S}$ announces the policy vector $P_{t}=\left\{\tau_{t}^{S a}, \tau_{t}^{S b}, \eta_{t}^{S A}, \eta_{t}^{S B}\right\}$

2. The citizens of group $S_{t}$ decide to support, $s_{t}=1$ or not, $s_{t}=0$

3. All groups decide to switch activities or not, $z_{t}^{A}, z_{t}^{B} \in\{0,1\}$

4. If $s_{t}=1, P_{t}$ is implemented and payoffs are realized. Next period starts with $S_{t+1}=S_{t}$ with probability $\bar{\gamma}^{S}$ and the state switches with probability $1-\bar{\gamma}^{S}$.

5. If $s_{t}=0$, the leader is ousted immediately and the "revolt" vector $P_{r}=\{0,0,0,0\}$ is implemented. With probability $1-\underline{\gamma}^{S}$, group $S$ loses power and the next period starts with $S_{t+1}=-S_{t}$. Otherwise, the next period starts with a new leader from group $S$.

There are a number of features of the model that are worth stressing. First, note that collective action within a group is not an issue in this model. The focus of the argument is on the forces that allow rents to be appropriated by a weak leader instead of competed away by different elites inside the same group. Adding heterogeneity and a collective action problem would only help the current leader to steal even more, because he would find it easier to disrupt coordination. Second, and in the same spirit, I do not allow the leader access to any repression instrument: if he loses the support of his group, he is replaced at no explicit cost. Third, it is important to note that the excluded group 
in this model always tries to unseat the incumbent. This is a simplifying assumption introduced because the focus of the analysis is in explaining why the supporter group actually supports a kleptocratic ruler. To the extent that support from one group is sufficient to guarantee incumbency advantage and it is relatively easier to obtain support from the kin group of the leader, this assumption is without loss of generality. However, it does not capture cases in which the leader is forced to subsidize the opposition group because support from his own group is not enough.

Finally, note that no difference is made between democracy and dictatorship in the model. The evidence from Africa shows that democracies have not behaved differently than dictatorships at the time of supporting kleptocracies and corruption ${ }^{15}$.

\subsection{Definition of Equilibrium}

The equilibrium concept to be used is (pure strategy) Markov Perfect Equilibrium. In this type of equilibria, strategies can only be contingent on the payoff-relevant state of the world and the prior actions taken within the same period.

As has been described above, the state space of this economy includes only two elements, $\Theta=\{A, B\}$, denoting whether power is captured by group $A$ or group $B$ at the beginning of period $t$. Denote the state at each period by $S_{t}$, where obviously $S_{t} \in \Theta$, $\forall t=0,1,2 \ldots$. Assume that each group has a set of potential leaders from which replacements will be drawn randomly. Call these two sets of leaders $\Delta^{A}$ and $\Delta^{B}$. At any point in time, the leader in power is denoted by $L^{A}$ or $L^{B}$ depending on the group he was drawn from. Denote by ${ }^{\sim} L^{A}$ the potential leaders that belong to $\Delta^{A}$ but are not currently in power. ${ }^{\sim} L^{B}$ is defined symmetrically. The strategy of the current leader $L^{A}$ is denoted by $P^{A}$ and it is a four-tuple $\left\{\tau^{A a}, \tau^{A b}, \eta^{A A}, \eta^{A B}\right\} \in \mathbb{R}_{+}^{4}$ when $S_{t}=A$. When either $S_{t}=B$ or $S_{t}=A$ but a leader belongs to ${ }^{\sim} L^{A}$, his set of strategies is empty. The symmetric definition holds for the strategies of leaders $L^{B}$.

\footnotetext{
${ }^{15}$ See Jackson and Rosberg (1982) or Mbaku (2000) among others.
} 
The strategy of group $A$ is denoted $\sigma^{A}\left(S, P^{S}\right)$ and depends on both the state of political capture and the policy vector proposed by the leader. It determines two actions, $\left\{s^{A}, z^{A}\right\}$ that have been defined above as the decision to support and the decision to switch economic activities. If $S_{t}=A, s^{A} \in\{0,1\}$. Therefore, if the leader is from group $A$, his group can decide to give him support or to subvert his authority. On the other hand, if $S_{t}=B, s^{A}=\emptyset . z^{A} \in\{0,1\}$ independently of the state. The symmetric definition holds for the strategy space of citizens of group $B$.

State transitions work as follows: whenever $s_{t}^{S}=1$, there is support and $S_{t+1}=S_{t}$ with probability $\bar{\gamma}^{S}$ and the state switches with probability $1-\bar{\gamma}^{S}$. If $s_{t}^{S}=0$, that is, if there is no support, $S_{t+1}=S_{t}$ with probability $\underline{\gamma}^{S}$. Denote this transition function $T\left(\sigma^{S}, S\right)$.

A (pure strategy) Markov Perfect Equilibrium for this game is a combination of strategies denoted by $\left\{\tilde{P}^{A}, \tilde{P}^{B}, \tilde{\sigma}^{A}, \tilde{\sigma}^{B}\right\}$ such that all four strategies are best responses to the other three for all possible states. In particular, consider the following set of Bellman equations:

$$
\begin{aligned}
V^{A}(S) & =\max _{\sigma^{A}}\left\{C^{A}\left(S, \tilde{P}^{S}, \sigma^{A}\left(S, P^{S}\right), \tilde{\sigma}^{B}\right)+\delta \sum_{S \in \Theta} V^{A}\left(S^{\prime}\right) T\left(\sigma^{S}, S\right)\right\} \\
V^{B}(S) & =\max _{\sigma^{B}}\left\{C^{B}\left(S, \tilde{P}^{S}, \sigma^{B}\left(S, P^{S}\right), \tilde{\sigma}^{A}\right)+\delta \sum_{S \in \Theta} V^{B}\left(S^{\prime}\right) T\left(\sigma^{S}, S\right)\right\} \\
W_{L^{A}}^{A}(A) & =\max _{P^{A}}\left\{U^{A}\left(P^{A}, \tilde{\sigma}^{A}, \tilde{\sigma}^{B}\right)+\delta \sum_{S \in \Theta} W_{\Delta}^{A}\left(S^{\prime}\right) T\left(\tilde{\sigma}^{A}\left(A, P^{A}\right), A\right)\right\} \\
W_{L^{B}}^{B}(B) & =\max _{P^{B}}\left\{U^{B}\left(P^{B}, \tilde{\sigma}^{B}, \tilde{\sigma}^{A}\right)+\delta \sum_{S \in \Theta} W_{\Delta}^{B}\left(S^{\prime}\right) T\left(\tilde{\sigma}^{B}\left(B, P^{B}\right), B\right)\right\}
\end{aligned}
$$

where $C^{j}$ denotes the consumption of citizen $j$ as a function of the state $S$ and the strategies of the leader in power and both sets of citizens. $V^{j}(S)$ denotes the value function for citizen $j$ in state $S$. $W_{L^{S}}^{i}(S)$ denotes the value function for leader from group $i$ in state $S$, when he is the current leader $L^{S}$. To complete the definition, note that $W_{\Delta}^{A}(B), W_{\sim^{A}}^{A}(A), W_{\Delta}^{B}(A)$ and $W_{\sim^{B}}^{B}(B)$ are completely independent of any decision 
that the particular leader could take. They only depend on the probability that, in equilibrium, a particular leader will be in power in the future. As a consequence, these are not interesting strategic objects in this game. A Markov Perfect Equilibrium is thus a combination of strategies $\left\{\tilde{P}^{A}, \tilde{P}^{B}, \tilde{\sigma}^{A}, \tilde{\sigma}^{B}\right\}$ such that $\tilde{\sigma}^{A}$ solves $(1), \tilde{\sigma}^{B}$ solves (2), $\tilde{P}^{A}$ solves (3) and $\tilde{P}^{B}$ solves (4).

\section{Analysis}

Assume without loss of generality that $S_{t}=A$. The equilibrium is characterized by backwards induction within each stage game. Hence, I examine first the decision to switch the sector of production. Take $B$ producers first. Note that the decision to switch does not affect continuation utilities, hence only the static difference in payoffs is relevant. After observing the policy vector $P_{t}$, they will switch sector only if the loss in wealth is smaller than the difference in taxation. Formally,

$$
z_{t}^{B}=1 \text { iff } \omega^{b}-\tau^{A b}<\omega^{b}-\theta^{B}-\tau^{A a}
$$

The ruler wants to avoid this switch because it reduces revenue. Hence, this ability to switch provides an upper bound on the differential taxation that the ruler can levy on group $B$. The effective constraint on the ruler will thus be

$$
\tau^{A b} \leq \theta^{B}+\tau^{A a}
$$

The equivalent restriction for group $A$ is then

$$
\tau^{A a} \leq \theta^{A}+\tau^{A b}
$$

Obviously, both restrictions cannot be binding at the same time.

I examine now the decision to support by $A$ members. Note that the leader is the first 
player to act in the stage game. As a consequence, since strategies can only be conditional on the state of the economy, a leader $L^{A}$ always proposes the same policy vector $P^{A}$. Upon observing $P^{A}$, if they support $\left(s_{t}=1\right), A$ supporters obtain:

$$
\omega^{a}-\tau^{A a}+R\left(\eta^{A A}\right)+\delta \bar{\gamma}^{A} V^{A}(A)+\delta\left(1-\bar{\gamma}^{A}\right) V^{A}(B)
$$

Alternatively, if they withdraw their support $\left(s_{t}=0\right)$ they expect:

$$
\omega^{a}+\delta \underline{\gamma}^{A} V^{A}(A)+\delta\left(1-\underline{\gamma}^{A}\right) V^{A}(B)
$$

Hence the support condition reduces to:

$$
\tau^{A a}-R\left(\eta^{A A}\right) \leq \delta\left(\bar{\gamma}^{A}-\underline{\gamma}^{A}\right)\left(V^{A}(A)-V^{A}(B)\right)
$$

Note that the ruler will always satisfy this constraint by subgame perfection. Not satisfying it gives him no benefit because in the period he is thrown out he already receives 0 utility (and he obtains 0 forever after). Condition (7) embodies the "Politics of Fear" mechanism. Note that when the left hand side is positive, the ruler is actually reducing the utility of his supporters. The right hand side of the condition is positive when $V^{A}(A)-V^{A}(B)>0$, namely when the group fares worse under the leadership of another group than under a leader from their midst. This gap creates the fear that allows the ruler to extract resources from his supporters. The bigger is the gap in discounted future payoffs, the more the current ruler can extract before being held accountable. The mapping between the difference in future utilities and today's rent extraction is multiplied by $\left(\bar{\gamma}^{A}-\underline{\gamma}^{A}\right)$, the incumbency advantage that the group as a whole loses when it decides to replace the leader. The more the group's hold on power is dependent on the current ruler, the more he can exploit his position ${ }^{16}$.

\footnotetext{
${ }^{16}$ This is a partial equilibrium result. In section 3.3 the full effect of $\left(\bar{\gamma}^{A}-\underline{\gamma}^{A}\right)$ and $\left(\bar{\gamma}^{B}-\underline{\gamma}^{B}\right)$ is shown to be even more important as fear amplifies across groups.
} 
For notational simplicity, and because the values will be determined in equilibrium, denote $\Phi^{A}=\delta\left(\bar{\gamma}^{A}-\underline{\gamma}^{A}\right)\left(V^{A}(A)-V^{A}(B)\right)$. With this simplification, the problem that a ruler $L^{A}$ solves at the beginning of each period is the following:

$$
\begin{aligned}
& \max _{\left\{\tau^{A a}, \tau^{A b}, \eta^{A A}, \eta^{A B}\right\}} \pi^{A}\left(\tau_{t}^{A a}-\eta_{t}^{A A}\right)+\left(1-\pi^{A}\right)\left(\tau_{t}^{A b}-\eta_{t}^{A B}\right)+\delta \bar{\gamma}^{A} W_{L^{A}}^{A}(A) \\
& \text { subj.to } \tau^{A b} \leq \theta^{B}+\tau^{A a} \\
& \tau^{A a} \leq \theta^{A}+\tau^{A b} \\
& \tau^{A a}-R\left(\eta^{A A}\right) \leq \Phi^{A} \\
& 0 \leq \eta^{A B}
\end{aligned}
$$

This program takes as given the equilibrium continuation values of the game and solves for the best policy vector that the ruler can propose given the two no switching constraints, (5) and (6), and the need to keep support from his group. Since (5) and (6) are respected, by subgame perfection there is no switching. Note that $z^{A}=z^{B}=0$ is already taken into account in the objective function of the ruler. Lemma 1 provides the solution to this program and is proved in the appendix.

Lemma 1 The solution of program (8) has the following structure:

$$
\begin{aligned}
\eta^{A B} & =0 \\
R^{\prime}\left(\eta^{A A}\right) & =\pi^{A} \\
\tau^{A a} & =\Phi^{A}+R\left(\eta^{A A}\right) \\
\tau^{A b} & =\theta^{B}+\Phi^{A}+R\left(\eta^{A A}\right)
\end{aligned}
$$

The structure of this solution is intuitive once it is clear that, at the optimum, all the constraints of the program except from the second one are binding. First, it is obvious that $\eta^{A B}=0$. The reason is that providing patronage good to the excluded group is 
costly and yields no benefit, since what is critical is the support from the leader's group. Moreover, note that the leader is maximizing rent extraction. Hence, the third constraint is binding because it puts an upper bound to the amount of rent extraction from the leader's group. Given the amount of taxation to the supporter group, the first constraint can be read as an upper bound to the amount of taxation on the excluded group and thus it is also binding at the optimum. In intuitive terms, the ruler extracts from his group just to the point of subversion and given that, he overtaxes the excluded group just to the point in which they would switch activities.

The optimal level of taxation depends on $\Phi^{A}$ and hence on future play, but this is not the case for optimal patronage provision. From (9) it is clear that patronage is overprovided to the supporter group. Note that, given the technology, a social planner would provide patronage to the point where $R^{\prime}\left(\eta^{A A}\right)=1$. This is the point where the marginal return to patronage equals the marginal cost of public revenue. Why does the leader overprovide costly patronage to his supporters?

The answer lies in the fact that the switching constraint for group $B$ is binding. As a consequence, any increase in $\tau^{A a}$ allows the ruler to increase $\tau^{A b}$ on a one-to-one basis. Constraint (7) shows that increasing $R\left(\eta^{A A}\right)$ and $\tau^{A a}$ in parallel maintains the support of the group, leaving supporters indifferent. However, the ruler is not indifferent: every unit of patronage to his group costs him only $\pi^{A}<1$, but it allows him to increase taxation to all groups, which means that his return is 1 . As a consequence of this imbalance, he overprovides patronage to his followers and overtaxes both his group and his opponents. Since the disparity between $\pi^{A}$ and 1 is the reason for this inefficiency, this distortion is worse the narrower the basis of support of the ruler (the smaller $\pi^{A}$ ).

From (11), the excluded group is discriminated not only in terms of patronage, but also in terms of taxation. However, to say something about the level of taxation in equilibrium I need to fully solve for the dynamic equilibrium. For notational simplicity, denote $\Psi^{i}=\frac{\delta\left(\bar{\gamma}^{i}-\underline{\gamma}^{i}\right)}{1+\delta\left(1-\bar{\gamma}^{A}-\bar{\gamma}^{B}\right)}$. Proposition 1 states the final result: 
Proposition 1 This model presents a unique MPE. In equilibrium, in state $S=A$ (when $S=B$ the expressions are symmetric):

1. $L^{A}$ proposes the following policy vector $P^{M P E}$ :

$$
\begin{aligned}
\eta^{A A} \equiv & \eta_{*}^{A} \text { such that } R^{\prime}\left(\eta_{*}^{A}\right)=\pi^{A} \\
\eta^{A B}= & 0 \\
\tau^{A a}= & \frac{\Psi^{A}\left(1+\Psi^{B}\right) \theta^{A}+\Psi^{A} \Psi^{B} \theta^{B}}{1+\Psi^{A}+\Psi^{B}}+ \\
& +\frac{\left(1+\Psi^{A}\right)\left(1+\Psi^{B}\right) R\left(\eta_{*}^{A}\right)+\Psi^{A}\left(1+\Psi^{B}\right) R\left(\eta_{*}^{B}\right)}{1+\Psi^{A}+\Psi^{B}} \\
\tau^{A b=} & \frac{\Psi^{A}\left(1+\Psi^{B}\right) \theta^{A}+\left(1+\Psi^{A}\right)\left(1+\Psi^{B}\right) \theta^{B}}{1+\Psi^{A}+\Psi^{B}}+ \\
& +\frac{\left(1+\Psi^{A}\right)\left(1+\Psi^{B}\right) R\left(\eta_{*}^{A}\right)+\Psi^{A}\left(1+\Psi^{B}\right) R\left(\eta_{*}^{B}\right)}{1+\Psi^{A}+\Psi^{B}}
\end{aligned}
$$

2. The citizens of group $A$ support the ruler $\left(s^{A}=1\right)$ if he proposes $P^{M P E}$ and oust him if he proposes any other policy vector that provides less instantaneous utility..

3. $z^{A}=0$ only if $\tau^{A a} \leq \theta^{A}+\tau^{A b}$ and $z^{B}=0$ only if $\tau^{A b} \leq \theta^{B}+\tau^{A a}$

The appendix contains the proof to this proposition. Here I concentrate on the substantive predictions of the model and how to interpret the result and relate it to the facts obseved in Africa.

\subsection{Policy Determination and Ethnic Bias}

This unique MPE of the model provides a framework to understand many features of the post-colonial political economy of Africa.

First, as I discussed above, the model endogenously generates inefficient policies. Note that in the simple framework proposed here, the unique potential source of inefficiency is the excessive allocation of patronage to a particular group. This feature of the equilibrium helps explain the patterns of inefficient taxation and inefficient transfers coexisting in the 
same group highlighted in the seminal work by Bates (1981) for agricultural policies in tropical Africa. The model shows that the need to buy support while extracting resources implies that the optimal policy by the ruler is to tax both groups and then return some patronage to the supporters, even if it is highly wasteful. This has been a general pattern of statism in Africa $^{17}$.

Second, the model predicts a very strong bias in the allocation of public funds. The excluded group receives no public benefits while the supporter group receives public resources beyond the optimal point. The use of public money in the form of bureaucratic posts, infrastructure or even access to schools as a form of patronage, as well as the ethnic bias in the allocation of these goods has been widely documented in Africa. Gikuyus and later Kalenjin in Kenya, northern groups in both Nigeria and Uganda or Tutsis in Burundi are just salient examples that have reproduced across the continent. In the Congo, Mobutu filled the higher ranks of the military and civil service with natives of his province, Equateur. The bias in favor of the ruling group is reported to be one of the basic sources of resentment between ethnic groups ${ }^{18}$.

Third, the bias is not only present in the allocation of patronage: taxation is also differential across groups. In particular, in addition to taxes levied on the supporter group, the model shows that the excluded group is expropriated from the specific share of its wealth. Bates (1981) and Bates (1989) provide evidence of this pattern: in Ghana and Uganda, among other examples, the coalition that supported the leader extracted resources from the coffee and cocoa planters. These are crops that involve substantial specific long term investment. On the contrary, in Kenya the Gikuyu controlled the coffee growing parts of the country, and hence the discrimination against these crops was much less evident.

The model also predicts that a change in the group controlling power should be followed

\footnotetext{
${ }^{17}$ See Collier and Gunning (1999) or Easterly and Levine (1997) and the references thereof for a description of the excess inefficient intervention.

${ }^{18}$ See Horowitz (1985) and Bates (1983). Also, see Collier and Garg (1999) which document that ethnic and kin relations are rewarded with higher wages in the public sector.
} 
by a change in taxation, spending and allocation of public resources. These patterns are widely documented in Africa. For instance, the ascension to power by Moi in Kenya was followed by a substitution of Gikuyus by Kalenjin in all echelons of the state ${ }^{19}$. In Ghana, cocoa has been heavily taxed by all governments, civil and military, except the one headed by Kofi Busia, a native from the Ashanti region which contains a large share of smallholders that grow cocoa. In Cameroon, the substitution of Ahidjo in 1982 unleashed another deep ethnic purge of the bureaucracy. Similar dynamics are found in Nigeria.

This pattern of discrimination both in raising revenue and in public expenditures supports the vision that a particular ethnic group has the government captured ${ }^{20}$. However, the model suggests that the actual benefits of such capture are not spread throughout the group. The particular elite that holds power extracts so many resources that part of this money comes from the pockets of non-elite members of the group. In equilibrium, $\Phi^{A}>0$ which implies that the ruler is able to reduce his followers' utility. The next subsection studies the determinants of $\Phi^{A}$. Wa Wamwere (2003) describes this absence of balance in the reception of spoils within a group in a colorful way:

"The cream of government service goes to the ruling ethnic elites, the crumbs to the lesser ethnic elites, and dust to members of the so-called ruling ethnic community" and "Among the Gikuyu of Kenya, the approving masses are called grill lickers, njuna ndara".

Fourth, the results of the model rationalize the existence of kleptocratic elites supported by masses of impoverished ethnic followers. Even though in absolute terms the masses are made worse off by the existence of rent-creating policies, in relative terms it is much better to belong to the group in power than to the excluded group, and hence they are willing to defend the status quo vis à vis a leader from another group. This fear of the future explains the puzzle of support. The members of a narrow elite around

\footnotetext{
${ }^{19}$ See Barkan and Chege (1989) for an account of the reallocation of posts and resources.

${ }^{20}$ That african citizens generally believe that this is the case is documented, for instance, in Posner (2005). See also Wa Wamwere (2003) for a powerful description of these ethnic dynamics.
} 
the leader are thus the ones extracting the lion's share of the rents that these inefficient policies create. Evidence of Kleptocratic tendencies abound in Africa, but Mobutu's Zaire is probably the most cited example. Sani Abacha in Nigeria or Daniel arap Moi in Kenya have been able to amass personal fortunes counted in the billions of dollars ${ }^{21}$. Consistent with this concentration of wealth at the highest levels of leadership, Africa is the continent with the highest capital flight ${ }^{22}$.

\subsection{Amplification of Kleptocracy}

The theoretical reason that allows kleptocratic regimes to obtain support in this model is summarized in expression (7). It makes clear that as long as the supporter group observes a difference between being in the supporter status and being excluded under the leadership of the opponent group, there is a surplus that the current leader can expropriate from his own supporters. In addition, the more a leader can extract from his supporters, the more he can extract from the excluded group, thanks to (5) being binding in equilibrium. As a consequence, there is an amplification effect of any characteristic of the economy that allows one type of ruler to steal.

To see this amplification mechanism, assume that $L^{A}$ is in power and the institutional or economic technology of this society changes so that a potential $L^{B}$ will now able to steal more from his group if he is ever in power. An $A$ citizen understands that, in equilibrium, this will mean that should she ever fall into an excluded status, her plight will be worse. This reduces $V^{A}(B)$ in equilibrium. This increases the fear of turnover which in the model is captured by a loosening of the support constraint $(7)$ for $L^{A}$. As a consequence, $L^{A}$ is able to increase $\tau^{A a}$ to the point where his supporters are again indifferent. Hence increasing the capacity of $L^{B}$ to steal makes $A$ supporters worse off even when $L^{A}$ is in power because not supporting entails taking a lottery that becomes much less favorable, since both $V^{A}(A)$ and $V^{A}(B)$ have been reduced. This amplification mechanism is at the

\footnotetext{
${ }^{21}$ See Ayittey (1992), Wa Wamwere (2003), Mbaku (2000) or any account of corruption in Africa.

${ }^{22}$ Collier and Gunning (1999)
} 
core of the comparative statics developed below and it is the reason why in the expressions for equilibrium taxation in Proposition 1 the economic and institutional characteristics of both groups appear.

Expression (12) can be rewritten to identify the substantive forces that allow the leader to reduce the utility of his own group:

$$
\tau^{A a}=\frac{\Psi^{A}\left(1+\Psi^{B}\right) \theta^{A}+\Psi^{A} \Psi^{B} \theta^{B}}{1+\Psi^{A}+\Psi^{B}}+\frac{\Psi^{A} \Psi^{B} R\left(\eta_{*}^{A}\right)+\Psi^{A}\left(1+\Psi^{B}\right) R\left(\eta_{*}^{B}\right)}{1+\Psi^{A}+\Psi^{B}}+R\left(\eta_{*}^{A}\right)
$$

The gap between $\tau^{A a}$ and $R\left(\eta_{*}^{A}\right)$ is exactly $\Phi^{A}$. The forces that allow leaders to create a wedge between supporters and excluded are twofold. First, their ability to discriminate in taxation given by $\theta^{A}$ and $\theta^{B}$. The effect of this ability on the capacity to extract resources appears in the first summand in expression (14). Second, their capacity to allocate patronage, which drives the second summand in (14). Hence, the two effects appear in additively separable terms. If the ethnic structure of a given society does not coincide with an economic sectorial cleavage or there are no important specificities in the economy (this would be a case in which $\theta^{A}$ and $\theta^{B}$ are small) the ruler finds it difficult to discriminate in taxation and hence the first summand would be small. However, patronage would still make a difference in the utility of his supporters and hence he would still be able to extract some rents.

The net amount of funds that the leader $L^{A}$ is able to extract equals $X^{A}=\Phi^{A}+$ $R\left(\eta_{*}^{A}\right)+\left(1-\pi^{A}\right) \theta^{B}-\pi^{A} \eta_{*}^{A}$. By the envelope theorem, all the interesting effects enter through $\Phi^{A}$ :

$$
\begin{aligned}
\frac{\partial X^{A}}{\partial \theta^{A}} & =\frac{\partial \Phi^{A}}{\partial \theta^{A}}=\frac{\Psi^{A}\left(1+\Psi^{B}\right)}{1+\Psi^{A}+\Psi^{B}}>0 \\
\frac{\partial X^{A}}{\partial \theta^{B}} & =\frac{\partial \Phi^{A}}{\partial \theta^{B}}+\lambda=\frac{\Psi^{A} \Psi^{B}}{1+\Psi^{A}+\Psi^{B}}+1-\pi^{A}>0
\end{aligned}
$$

These results imply that starting from a situation with low $\theta^{A}$ and $\theta^{B}$, an increase in the specificity of income anywhere in the economy increases equilibrium misbehavior 
by the ruler. In the case of a citizen of group $A$, and increase in $\theta^{A}$ implies increased expropriation by a potential $L^{B}$. As a consequence, she allows her leader to steal more from her.

An increase in $\theta^{B}$ has two effects: the direct one comes from the tax markup that $L^{A}$ charges on group $B$. In addition, there is the amplification effect detailed above: an increase in $\theta^{B}$ means that $B$ citizens will be afraid of losing power if they ever regain it. Hence a $B$ leader will be able to steal more from them and, as a consequence, steal more from $A$ citizens that would be excluded in that case. Therefore an increase in $\theta^{B}$ allows $L^{A}$ to reduce his supporters' utility further. In economies where this specificities are important, such as those where education levels are low, ethnic networks are important and tree-crops are the backbone of agriculture, rulers are able to exploit this hold-up problem to their advantage. Note that these characteristics are pervasive in sub-Saharan Africa.

The weakness of institutions is proxied in the model by $\bar{\gamma}^{i}$ and $\bar{\gamma}^{i}-\underline{\gamma}^{i}$. A high $\bar{\gamma}^{i}$ implies a regime that is very difficult to dislodge as long as core supporters keep their defense ${ }^{23}$. Moreover, $\bar{\gamma}^{i}-\underline{\gamma}^{i}$ captures the degree of personalistic rule and the instability of succession processes: the larger is this difference, the bigger is the chance of a regime change every time there is a leader succession. Hence, it is informative to analyze the comparative statics of rent extraction with respect to these set of parameters. In particular, it is easy to show that: ${ }^{24}$

\footnotetext{
${ }^{23}$ When $\bar{\gamma}^{i}$ is higher than the share of the supporting population, institutions are not enforcing representativity and there is incumbency advantage.

${ }^{24}$ None of these comparative statics is ambiguous. The expressions for each partial derivative are listed in the Appendix.
} 


$$
\begin{aligned}
& \frac{\partial X^{A}}{\partial \bar{\gamma}^{A}}=\frac{\partial \Phi^{A}}{\partial \bar{\gamma}^{A}}=\frac{\partial \Phi^{A}}{\partial \Psi^{A}} \frac{\partial \Psi^{A}}{\partial \bar{\gamma}^{A}}+\frac{\partial \Phi^{A}}{\partial \Psi^{B}} \frac{\partial \Psi^{B}}{\partial \bar{\gamma}^{A}}>0 \\
& \frac{\partial X^{A}}{\partial \bar{\gamma}^{B}}=\frac{\partial \Phi^{A}}{\partial \bar{\gamma}^{B}}=\frac{\partial \Phi^{A}}{\partial \Psi^{A}} \frac{\partial \Psi^{A}}{\partial \bar{\gamma}^{B}}+\frac{\partial \Phi^{A}}{\partial \Psi^{B}} \frac{\partial \Psi^{B}}{\partial \bar{\gamma}^{B}}>0 \\
& \frac{\partial X^{A}}{\partial \underline{\gamma}^{A}}=\frac{\partial \Phi^{A}}{\partial \underline{\gamma}^{A}}=\frac{\partial \Phi^{A}}{\partial \Psi^{A}} \frac{\partial \Psi^{A}}{\partial \underline{\gamma}^{A}}+\frac{\partial \Phi^{A}}{\partial \Psi^{B}} \frac{\partial \Psi^{B}}{\partial \underline{\gamma}^{A}}<0 \\
& \frac{\partial X^{A}}{\partial \underline{\gamma}^{B}}=\frac{\partial \Phi^{A}}{\partial \underline{\gamma}^{B}}=\frac{\partial \Phi^{A}}{\partial \Psi^{A}} \frac{\partial \Psi^{A}}{\partial \underline{\gamma}^{B}}+\frac{\partial \Phi^{A}}{\partial \Psi^{B}} \frac{\partial \Psi^{B}}{\partial \underline{\gamma}^{B}}<0
\end{aligned}
$$

From these comparative statics it is clear that the level of rent extraction is increasing in both $\left(\bar{\gamma}^{A}-\underline{\gamma}^{A}\right)$ and $\left(\bar{\gamma}^{B}-\underline{\gamma}^{B}\right)$. The first one follows from constraint $(7)$ : the leader can extract more resources from his followers the more their probability of keeping power depends on maintaining this particular leader. In other words, the incumbency advantage $\left(\bar{\gamma}^{A}-\underline{\gamma}^{A}\right)$ makes "fear" $\left(V^{A}(A)-V^{A}(B)\right)$ a real possibility and thus scales up its impact. However, the effect here is more important because it includes the amplification of fear discussed above. From this logic of amplification follows also the fact that $L^{A}$ can expropriate more the bigger is $\bar{\gamma}^{B}-\underline{\gamma}^{B}$.

Hence stealing increases with institutional uncertainty and personality-dependent control of power. In particular, the leader would like to reduce the grip on power of his followers if he is ousted, while at the same time strengthen his ethnic group position vis-à-vis the excluded group as long as he is in power. While these parameters depend on characteristics of the polity beyond the control of the ruler, such as the demographic ethnic balance, they certainly also depend on institutional factors. Even with a divided society a leader cannot extract much from the citizenry if the hold in power of a particular group and the stability of a particular regime does not depend on the personal links of the ruler on top. This reduction on personality dependent incumbency advantage is precisely a sign of institutional strength and hence it is not surprising that the margin to misbehave in strongly institutionalized polities is very much reduced.

However, even in strongly institutionalized settings voters face a similar dilemma. A 
strong ideological divide (for instance the one existing between conservatives and liberals in moral issues) can work as a group definition. In this case, how should a moral conservative voter punish a conservative candidate that he perceives as deviating ${ }^{25}$ ? If he tries to hold him accountable by witholding his vote, he is (marginally) increasing the probability of a liberal reaching power, which really reduces this voter's future utility. Hence some amount of shirking is tolerated by supporters before any punishment is implemented.

It follows that, with respect to this mechanism, the difference between a well-functioning democracy and the kleptocracies that are present in Africa is one of degree: strong institutions limit the extent to which a group can capture power and restrict the set of tools that the leader can use to widen the gap between supporters and the opposition. As a consequence, stealing or shirking in office is restrained. As institutions place less constraints on the leader and societal divisions grow wider, accountability of the rulers is weakened. In the case of Africa, both circumstances occur in their extreme form and, as a consequence, outright kleptocracy is sustainable.

Comparative statics with respect to the ethnic demographic balance are ambiguous. On the one hand, all the direct effects predict a reduction in stealing: increasing $\pi^{A}$ reduces the benefits from distorting the patronage good for two reasons. First, rents are reduced at each level of provision because it becomes more expensive to provide it. Moreover, the optimal level of distortion is reduced because the returns are reduced (less people in the excluded group to pay for it).

In addition, increasing $\pi^{A}$ reduces the fraction of population excluded, and hence reduces the extra revenue that comes from the extraction of their specific resources.

However, there is a third, indirect effect, that makes the overall effect ambiguous: increasing $\pi^{A}$ means that, should group $A$ ever lose power, a potential $L^{B}$ would be able to steal more: he would increase distortions in the allocation of $\eta_{*}^{B}$ because his basis of support would now be smaller. Using the same logic of amplification, this allows an

\footnotetext{
${ }^{25}$ Strong institutions affect the possibility of outright stealing in western countries. But there are many instances of ideological shirking or other ways in which the ruler extracts a personal benefit at a cost for his supporters.
} 
$L^{A}$ leader extra room for stealing. Explicitly, the partial derivative has the following expression:

$$
\frac{\partial X^{A}}{\partial \pi^{A}}=\frac{\Psi^{A} \Psi^{B}}{1+\Psi^{A}+\Psi^{B}} \frac{R^{\prime}\left(\eta_{*}^{A}\right)}{R^{\prime \prime}\left(\eta_{*}^{A}\right)}-\eta_{*}^{A}-\theta^{B}-\frac{\Psi^{A}\left(1+\Psi^{B}\right)}{1+\Psi^{A}+\Psi^{B}} \frac{R^{\prime}\left(\eta_{*}^{B}\right)}{R^{\prime \prime}\left(\eta_{*}^{B}\right)}
$$

The first two summands represent the rents lost from the ability to distort $\eta_{*}^{A}$ and the third is the direct loss that is a consequence of the smaller size of the excluded group. The last summand represents the indirect effect, and it is positive ${ }^{26}$. For general functional forms of $R($.$) this expression cannot be signed, but note that if R($.$) is a power function,$ $\frac{R^{\prime}(\eta)}{R^{\prime \prime}(\eta)}$ is increasing in $\eta$. Hence, if the third indirect effect ever dominates, it will do so at high levels of $\pi^{A}$. That is, when the $A$ group includes a wide majority of the population, the prospect of falling under a $B$ leader is most terrifying because $L^{B}$ will have a very narrow basis of support, and hence he will use extreme distortions of patronage to steal.

\subsection{Subgame Perfect Equilibria}

The unique MPE described above provides low levels of utility to both groups while leaders are able to escape with high amounts of rents. Hence it is an interesting question to ask whether strategies that condition on past history of play can generate better outcomes for the citizens at large. There are two interesting insights from the answer to this question.

First, the ability to of supporters to inflict future punishments on their leader will not help. In other words, the $A$ group citizens cannot reduce stealing in equilibrium from the different $L^{A}$ by conditioning their future play on past misbehavior by $L^{A}$. The reason is that the worst lifetime payoff that a leader can have is 0 , which is what he obtains by leaving the game. But this is the threat that is already supporting the MPE. Carrying this threat out at higher levels of utility is not credible, and hence cannot be part of a subgame perfect equilibrium. Therefore, punishment between a group and its elite cannot support a better equilibrium.

\footnotetext{
${ }^{26}$ Recall that it is assumed that $R^{\prime \prime}<0$
} 
Second, there is a set of strategies that can support better payoffs in equilibrium, but they require coordination among the citizens from the different groups. These equilibria can support first-best if $\delta$ is high enough.

Proposition 2 If $\delta$ is close enough to 1, the following strategies support first-best for the citizens of both groups. Without loss of generality assume that $S=A$.

1. $L^{A}$ proposes the following policy vector $P^{*}$ :

$$
\begin{aligned}
\tau^{A a} & =\tau^{A b}=\eta^{*} \\
\eta^{A A} & =\eta^{A B}=\eta^{*} \text { where } R^{\prime}\left(\eta^{*}\right)=1
\end{aligned}
$$

2. Group $A$ chooses $s=1$ only if the ruler proposes $P^{*}$ and there has been no deviation by any Group in the past

3. $z^{A}=0$ only if $\tau^{A a} \leq \theta^{A}+\tau^{A b}$ and $z^{B}=0$ only if $\tau^{A b} \leq \theta^{B}+\tau^{A a}$

4. If at any point in the past a Group did not choose $s=0$ when their ruler proposed a policy different than $P^{*}$, the play reverts to the MPE stated in Proposition 1

Even if $\delta$ is not high enough, these type of equilibria can sustain better payoffs for the citizens than the MPE. Hence, coordination across ethnic lines provides a way of escaping the trap of kleptocracy. This requires to trust the other group that they will oust their ruler when he steals from anybody. Unfortunately, trust is a rare commodity in a divided society. In the light of this proposition, it is not surprising that rulers in these countries put so much effort in keeping the divided status of their citizenry. This is the basis of the "Divide-and-Rule" strategy: as it is clear from the MPE, when groups do not trust each other, rulers can escape accountability. In this sense, this proposition shows that the division of society is a necessary condition for kleptocracy.

Post-colonial rulers were not the first ones using these strategies in Africa. Multiple academic accounts, among them Cooper (2002) and Horowitz (1985) describe the process 
by which ethnic separation became a basic strategy of domination by the colonial powers. Some groups where protected and allowed to thrive but at the same time they were demonised among the rest of the population. In reality, political reasons were paramount in decisions such as assigning Nilotes to the army and Bagandas to the civil service in Uganda. Examples of ethnic separation and discrimination included differential access to schooling and clearly delimited geographical authorities by tribal chiefs and reproduced throughout the continent. This process of separation and selective protection generated a basis of support for colonial presence but contributed dramatically to the creation of ethnic self-consciousness and resentment. These societies were, as a consequence, ripe for the exploitation of such divisions by their post-colonial leaders.

\section{Extensions}

\subsection{On Public Investment}

The evidence from Africa shows that governments overspend in wages and undertake very little of infrastructure construction ${ }^{27}$. In the previous sections wages are explicitly considered as sources of patronage that need to be pledged at every stage and hence have no durability. The model makes clear why this kind of patronage is overprovided in divided societies. A simple extension of the model clarifies why durable investments are neglected.

Assume that the policy vector $P_{t}^{S}=\left\{\tau^{A a}, \tau^{A b}, I^{A}\right\}$ includes now $I$, public investment. This investment contributes to a stock of public capital $K$. This stock evolves according to the following dynamics: $K_{t}=\varsigma K_{t-1}+I_{t-1}$. Hence, investment today increases the stock of public capital tomorrow and this capital depreciates at rate $1-\varsigma$. The stock of infrastructure provides a benefit $F(K)$ to the supporter group and $\beta F(K)$ to the excluded group, for $\beta \leq 1$. $\beta$ thus captures the degree of excludability of public infrastructure.

\footnotetext{
${ }^{27}$ See Collier and Gunning (1999) for an account of these patterns. See also Mbaku (2000) and Bates (1981) for some examples in Cameroon, Nigeria and Ghana of excess expenditure in wages.
} 
A pure public good would have $\beta=1$. Assume that $F^{\prime}>0$ and $F^{\prime \prime}<0$. If there is replacement of a leader there is no investment. Assume, finally, that when there is a revolt, the enjoyment of the public infrastructure is reduced to $\psi F(K)$, for $\psi \leq 1$. Hence $\psi$ captures the instantaneous cost of upheaval.

To simplify the analysis, and in particular the dynamics that a new state variable could introduce, assume that leaders have no financial constraints and their instantaneous utility is linear: $U_{t}^{A}=\pi^{A} \tau_{t}^{A a}+\left(1-\pi^{A}\right) \tau_{t}^{A b}-\left(K_{t+1}^{A}-\varsigma K_{t}^{A}\right)$. This implies that the optimal level of capital in steady state will be reached as soon as a leader has a chance to invest. As a consequence, a succession induces a transitiory that lasts only for one period. Hence I can set the problem in terms of the desired level of capital for next period $\tilde{K}^{A}$. In addition, assume that $\bar{\gamma}^{A}=\bar{\gamma}^{B}=1$, for expositional clarity (in this case, support from the group is enough to keep power with certainty).

The model can be solved in exactly the same way as the previous case ${ }^{28}$. In particular, the Markov Perfect Equilibrium has the same characteristics: the leader in power satisfies the constraint that makes his supporters indifferent between replacing him and supporting his rule. Hence, in equilibrium there is no replacement of the leadership. To examine explicitly the new support constraint, note that when supporters do support, $s_{t}=1$, they receive:

$$
\omega^{A}-\tau_{t}^{A a}+F\left(K_{t}^{A}\right)+\delta\left(\omega^{A}-\tau_{t+1}^{A a}+F\left(K_{t+1}^{A}\right)\right)+\delta^{2} V^{A}(A)
$$

On the other hand, if they withdraw support, $s_{t}=0$, they obtain:

$$
\begin{aligned}
& \omega^{A}+\psi F\left(K_{t}^{A}\right)+\delta\left(\underline{\gamma}^{A}\left[\omega^{A}-\tau_{t+1}^{A a}+F\left(\varsigma K_{t}^{A}\right)\right]+\left(1-\underline{\gamma}^{A}\right)\left[\omega^{A}-\tau_{t+1}^{B a}+\beta F\left(\varsigma K_{t}^{A}\right)\right]\right)+ \\
& +\delta^{2}\left(\underline{\gamma}^{A} V^{A}(A)+\left(1-\underline{\gamma}^{A}\right) V^{A}(B)\right)
\end{aligned}
$$

\footnotetext{
${ }^{28}$ The inclusion of a new state variable may create multiplicity of MPEa. For expositional ease I only analyze the equilibrium most similar to the previous case in which strategies are not conditional on the stock of capital.
} 
Hence, the support constraint, using stationarity, can be written as:

$$
\begin{aligned}
& \tau_{t}^{A a}+(\psi-1) F\left(K_{t}^{A}\right)+\delta\left(1-\underline{\gamma}^{A}\right)\left[\tau_{t+1}^{A a}-\tau_{t+1}^{B a}\right]-\delta F\left(K_{t+1}^{A}\right)+\delta\left[\underline{\gamma}^{A}+\left(1-\underline{\gamma}^{A}\right) \beta\right] F\left(\varsigma\left(K_{t} f_{t}^{A}\right)\right. \\
\leq & \frac{\delta^{2}}{1-\delta}\left(1-\underline{\gamma}^{A}\right)\left[V^{A}(A)-V^{A}(B)\right]
\end{aligned}
$$

The ruling leader faces a problem identical to (8) with an additional choice variable, $K_{t+1}^{A}$ and the support constraint replaced by (15). The first order conditions from this program imply that the chosen level of $K_{t+1}^{A}$ will be determined implicitly by the following expression:

$$
F^{\prime}\left(K_{t+1}^{A}\right)(2-\psi)-\delta\left[\underline{\gamma}^{A}+\left(1-\underline{\gamma}^{A}\right) \beta\right] \varsigma F^{\prime}\left(\varsigma K_{t+1}^{A}\right)=\frac{1}{\delta}-\varsigma
$$

To interpretat this expression it is better to analyze it in two parts: $F^{\prime}\left(K^{A}\right)(1-\psi)$ is the marginal effect on $\tau^{A a}$ caused by the contemporaneous effects of upheaval: if there is no revolt, supporters enjoy the whole return from infrastructure, while subversion reduces it to a fraction $\psi . \quad F^{\prime}\left(K^{A}\right)-\delta\left[\underline{\gamma}^{A}+\left(1-\underline{\gamma}^{A}\right) \beta\right] \varsigma F^{\prime}\left(\varsigma K^{A}\right)$ is the effect on $\tau^{A a}$ caused by the effect of upheaval on next period's returns: if they support, citizens will receive the full return per period, $F\left(K^{A}\right)$ while ousting the leader has two effects. First, it will reduce the stock of capital tomorrow to $\varsigma K^{A}$ and second, the citizens enter on the lottery for the replacement, which means that their expected enjoyment is scaled down by $\left[\underline{\gamma}^{A}+\left(1-\underline{\gamma}^{A}\right) \beta\right]$. Note that the equivalent expression for a social planner that would take the welfare of both groups into account would be:

$$
\left[\pi^{A}+\beta\left(1-\pi^{A}\right)\right] F^{\prime}\left(K_{t+1}^{A}\right)=\frac{1}{\delta}-\varsigma
$$

Assuming that $F(K)=K^{\alpha}$, for $\alpha<1$, allows an explicit look at the gap between the capital level of the leader and the socially optimal level. Denote by $\tilde{K}^{A}$ the level chosen by the ruler and by $K^{*}$ the level chosen by the social planner. The ratio of both expressions 
satisfies:

$$
\left(\frac{\tilde{K}^{A}}{K^{*}}\right)^{1-\alpha}=\frac{2-\psi-\delta\left[\underline{\gamma}^{A}+\left(1-\underline{\gamma}^{A}\right) \beta\right] \varsigma^{\alpha}}{\pi^{A}+\beta\left(1-\pi^{A}\right)}
$$

Note that this ratio is decreasing in $\beta, \psi$ and $\varsigma$. The ruler invests relatively more in capital the faster the good depreciates and the less useful it is during upheaval. These two forces are ignored by the social planner. There are political reasons behind these effects: reduction in $\varsigma$ and/or $\psi$ increases the costs of succession. In particular, one of the costs of upheaval is the absence of investment for one period. Obviously, this is not a large cost if depreciation is very slow and, as a consequence, investment is very small each period. On the contrary, when $\varsigma$ approaches $0, K$ behaves very similarly to $\eta$, which is overprovided.

Excludability $(\beta)$ has opposite effects in the ruler and the social planner. When supporters know that they can be excluded from enjoying public capital if there is a succession, they are more eager to defend the current regime. Hence an increase in $\beta$ reduces investment by the leader. For the social planner, investment is increasing in $\beta$ because more people are able to enjoy the public infrastucture and social welfare increases while costs remain the same.

Finally, note that when $\beta=\psi=\varsigma=1$, the relative level of capital provided by the leader is very low, because $\delta$ is close to 1 .

The absence of investment in infrastructure can thus be interpreted under the light of the model. The political survival of the leader hinges on creating a network of supporters personally dependent on his presence in power. Building a road gives no advantage to the leader, because the day a coup ousts him from power the road will still be there for everybody to enjoy. The same is true for a hospital or a school. Hence there is underprovision of capital when it is very permanent and/or it is not excludable. ${ }^{29}$

\footnotetext{
${ }^{29}$ This argument for the existence of inefficient clientelist networks based on "flow" goods such as expanded public employment versus "stock" goods such as infrastructure is present in Robinson and Verdier (2002). The framework presented here links this phenomenon to the weak institutions and ethnic divisions present in Africa.
} 


\subsection{On Patterns of Ethnic Violence}

The logic of the model shows that the leader can enlist the support of his ethnic group by making sure that ethnic supporters disproportionately fear the prospect of being under the rule of another group. The ruler can contribute to this fear by acting heavy-handedly against oppressed groups, and making sure that his rule is seen by everyone as ethnically based. Ayittey (1999) describes how ordinary Krahn people feared the demise of Samuel K. Doe, a fellow Krahn, in Liberia. Even though they did not receive any of the spoils from government, the fact that the regime was clearly almost exclusively Krahn, and that it was engaged in acts of pillaging, rape and atrocities against the other groups made clear to them that retribution would be against all Krahn the day the regime was defeated. Obviously, this made Krahn people collaborate in defending the regime, even in the absence of any spoil from the government. ${ }^{30}$ In this way, ethnic violence can be used to enlist otherwise reluctant members of the group in the defense the regime ${ }^{31}$.

To see how the prospect of violence is equivalent to patronage links to the ruler the model can be extended in a very simple way. Assume that by oppressing the excluded group, the leader can contribute to the level of enmity that the excluded group holds against the supporter group. Call $E_{t}^{A B}$ the level of enmity that group $B$ has against $A$. Assume that this variable evolves in the following way $E_{t}^{A B}=\phi E_{t-1}^{A B}+o_{t-1}^{A B}$, where $o_{t}^{A B}$ denotes the amount of costly oppression that $L^{A}$ inflicts on $B$ citizens. ${ }^{32}$ Assume further that living under the leadership of a group that stocks enmity against you causes disutility, which is captured by $\Pi\left(E^{A B}\right)$, with $\Pi^{\prime}>0, \Pi^{\prime \prime}<0$, and $\Pi(0)=0$.

Now, if supporters give support, $s_{t}=1$, they will receive ${ }^{33}$ :

$$
\omega^{A}-\tau_{t}^{A a}+R\left(\eta_{t}^{A A}\right)+\delta V^{A}(A)
$$

\footnotetext{
${ }^{30}$ See also Harden (1990)

${ }^{31}$ Political scientists agree in considering violence an important force in defining and separating groups because it prevents future interactions across ethnic lines. See, for instance, Fearon (1995).

${ }^{32}$ Glaeser (2005) microfounds the existence of hatred arguments in the electoral arena. I assume here that violence is a direct creator of enmity.

${ }^{33}$ Again, for simplicity the case shown assumes $\bar{\gamma}^{A}=\bar{\gamma}^{B}=1$
} 
If they replace the leader, $s_{t}=0$, they will receive:

$$
\omega^{A}+\Sigma_{t=1}^{\infty} \delta^{t}\left\{\underline{\gamma}^{A}\left(\omega^{A}-\tilde{\tau}^{A a}+R\left(\eta_{*}^{A}\right)\right)+\left(1-\underline{\gamma}^{A}\right)\left(\omega^{A}-\tilde{\tau}^{B a}-\Pi\left(E_{t}^{A B}\right)\right)\right\}
$$

Hence, the support constraint can be written as:

$$
\tau_{t}^{A a}-R\left(\eta_{t}^{A A}\right) \leq\left(1-\underline{\gamma}^{A}\right) \Sigma_{s=t+1}^{\infty} \delta^{s}\left(-\tilde{\tau}^{A a}+R\left(\eta_{*}^{A}\right)+\tilde{\tau}^{B a}+\Pi\left(E_{s}^{A B}\right)\right)
$$

Therefore, the leader maximizes $\Sigma_{t=1}^{\infty} \delta^{t}\left\{\pi^{A}\left(\tau_{t}^{A a}-\eta_{t}^{A A}\right)+\left(1-\pi^{A}\right) \tau_{t}^{A b}-\left(E_{t+1}^{A B}-\phi E_{t}^{A B}\right)\right\}$ under the usual no-switching constraints and (17). The optimal level of enmity that $L^{A}$ seeks is determined by:

$$
\left.\Sigma_{s=t+1}^{\infty}(\delta \phi)^{s} \Pi^{\prime}\left(\phi^{s} E_{*}^{A B}\right)\right)=\frac{1-\phi \delta}{1-\underline{\gamma}^{A}}
$$

This expression shows that the leader will cause a higher level of enmity the slower enmity disappears (the higher $\phi$ ), the smaller the time discounting (the higher $\delta$ ) and the bigger the chance that the supporters will lose control of power should they replace the leader (the lower $\underline{\gamma}^{A}$ ). The intuition is perfectly in line with the rest of the argument developed in the paper: $V^{A}(B)$ is smaller the slower the rate of forgiveness. Moreover, $V^{A}(B)$ is more probable when $1-\underline{\gamma}^{A}$ is small. Both effects make his supporters warier of entering into the replacement lottery and this allows the ruler to extract more resources.

To see that enmity behaves similarly to the capacity to discriminate in patronage, rename $\Lambda^{A B}=\left(1-\underline{\gamma}^{A}\right) \Sigma_{s=1}^{\infty} \delta^{s} \Pi\left(\phi^{s} E_{*}^{A B}\right)$. With this change of notation the model can be solved for the unique MPE which has the following expression for taxes extracted from the supporter group:

$$
\begin{gathered}
\tau^{A a}=\frac{\left(1+\zeta^{B}\right) \zeta^{A} \theta^{A}+\zeta^{B} \zeta^{A} \theta^{B}}{1+\zeta^{A}+\zeta^{B}}+ \\
+\frac{\left(1+\zeta^{B}\right) \zeta^{A} \Lambda^{B A}+\left(1+\zeta^{B}\right) \Lambda^{A B}+\left(1+\zeta^{A}\right)\left(1+\zeta^{B}\right) R\left(\eta_{*}^{A}\right)+\zeta^{A}\left(1+\zeta^{B}\right) R\left(\eta_{*}^{B}\right)}{1+\zeta^{A}+\zeta^{B}}
\end{gathered}
$$


where $\zeta^{A}=\left(1-\underline{\gamma}^{A}\right) \frac{\delta}{1-\delta}$ and $\zeta^{B}=\left(1-\underline{\gamma}^{B}\right) \frac{\delta}{1-\delta}$. Note that in this expression, the capacity to induce enmity enhances the capacity to steal in a similar way as the ability to discriminate in patronage. Kleptocracy can thus be supported by indiscriminate use of violence in the name of the group, as Samuel K. Doe's Liberia show.

This logic can be used to understand the scale of atrocities and ethnic cleansing in Rwanda in 1994. Prunier (1995) describes how the "hutu" regime of Habyarimana and the inner circle captained by his wife was besieged both by the Tutsi guerrillas of the RPF and the southern moderate hutu elites that were complaining at the level of corruption and kleptocracy concentrated in northern hands. By making the majority of the hutu population participate in the atrocities, the regime almost succeeded in doing two things. First they completely erased the northern-southern divide inside the hutu elites by either eliminating those hutus deemed too moderate or making them participate in the genocide. Second, the scale of atrocities against the tutsi minority was so horrific, that no hutu could accept the prospect of living under a tutsi leader for fear of equally horrible retribution. The massive scale of hutu refugee tides to Zaire is a testament to this strategy. This pattern of government sponsored ethnic violence, albeit in a somewhat smaller scale has been present in Uganda, Burundi ${ }^{34}$ and other countries in the region.

The logic of exclusion and replacement thus provides as a corollary a framework to understand some of the patterns of high and low level ethnic violence that plague deeply divided societies, especially when their governments define themselves in ethnic terms.

\section{Conclusion}

Post-colonial African citizens have suffered under kleptocracies that have imposed distortionary and rent-creating policies on their economies. However, accounts coincide in considering these regimes weak, which sheds doubt on the hypothesis that they have sur-

\footnotetext{
${ }^{34}$ See Lemarchand (1996) for an account of the seeds of violence and patterns of ethnic domination in Burundi.
} 
vived in power solely due to the use of force to oppress the whole population. On the contrary, parts of these populations have been mobilized into defending these kleptocratic regimes.

This paper proposes a coherent model of the political economy of such regimes. The main contribution of the analysis consists in showing that the political uncertainty of succession in weakly institutionalized settings can explain most of the political and economic

phenomena that characterize these regimes. In particular, since the use of patronage networks allow the leader to treat his ethnic group better than the opposition, ethnic supporters are keen in maintaining this relative superiority. Uncertainty in succession makes supporters reluctant to replace the leader and hence rents are not dissipated. In fact, the ruler is able to extract resources from all groups in society. From the analysis I derive a number of corollaries that are consistent with the degree of ethnic bias, bureaucratic inoperance and patterns of taxation and expenditures observed in such regimes.

The main lesson from the growing field of analysis of policy determinants in weakly institutionalized regimes is that their inefficiencies emerge because weak states impose a very particular set of contraints and needs on their rulers. The same is true for the political outcomes of such countries. Attempts at helping these economies have to take into account where the incentives of their leaders are (mis)placed. My analysis reveals that nominal democratization may not affect at all the basic forces sustaining absence of accountability. In particular, reform has to include effective constraints on the capacity of the leaders to treat ethnic groups differently, and it should include mechanisms directed to smoothing intra-group competition.

\section{References}

[1] Acemoglu, D. And Robinson, J. 2001. "Inefficient Redistribution." American Political Science Review, 95: 649-661. 
[2] Acemoglu, D. Robinson, J. and Verdier, T. 2004. "Kleptocracy and Divideand-Rule: a Model of Personal Rule." Journal of the European Economic Association, 2: $162-192$.

[3] Ayittey, G. 1992. Africa Betrayed. New York: St Martin's Press.

[4] Barkan, J. and Chege, M. 1989. "Decentralizing the State: District Focus and the Politics of Reallocation in Kenya." The Journal of Modern African Studies, 27: 431-453.

[5] Barro, R. 1973. "The control of politicians: an economic model." Public Choice, 14: $19-42$.

[6] Bates, R. 1981. Markets and States in Tropical Africa. Berkeley: University of California Press.

[7] Bates, R. 1983. "Modernization, Ethnic Competition, and the Rationality of Politics in Contemporary Africa." In State versus Ethnic Claims: African Policy Dilemmas, ed. Olurunsola, V. and Rothchild, D. Boulder, CO: Westview Press.

[8] Bates, R. 1989. Beyond the Miracle of the Market. New York: Cambridge University Press.

[9] Bates, R. 2000. "Ethnicity and Development in Africa: A Reappraisal." American Economic Review, 90: 131-134.

[10] Bates, R. and La Ferrara, E. 2001 "Political Competition in Weak States." Economics and Politics, 13: 159-184.

[11] Bratton, M. and van der Walle, N. 1997. Democratic Experiments in Africa: Regime Transitions in Comparative Perspective. Cambridge University Press.

[12] Caselli, F. and Coleman, J. 2002. "On the Theory of Ethnic Conflict." Unpublished Manuscript, Harvard University. 
[13] Chabal, P. And Daloz, J-P. 1999. Africa Works: Disorder as Political Instrument. Oxford: The International African Institute.

[14] Collier, P. And Garg, A. 1999. "On kin groups and wages in the Ghanaian labour market." Oxford Bulletin of Economics and Statistics, 61: 133-152.

[15] Collier, P. And Gunning J.W. 1999 "Explaining African Economic Performance." Journal of Economic Literature, 37: 64-111.

[16] Cooper, F. 2002. Africa since 1940: The Past of the Present. Cambridge: Cambridge University Press.

[17] Easterly, W. And Levine, R. 1997. "Africa's Growth Tragedy: Politics and Ethnic Divisions." Quarterly Journal of Economics, 111: 1203-1250.

[18] Easterly, W. 2002. The Elusive Quest for Growth: Economists' Adventures and Misadventures in the Tropics. Cambridge, MA: MIT Press.

[19] Ellman, M. And Wantchekon, L. 2000. "Electoral Competition under the Threat of Political Unrest." Quarterly Journal of Economics, 115: 499-531.

[20] Fafchamps, M. 2004. Market Institutions in Sub-Saharan Africa. Cambridge, MA: MIT Press.

[21] Fearon, J. 1995. "Ethnic War as a Commitment Problem." Typescript. Stanford University.

[22] Fearon, J. And Laitin, D. 1996. "Explaining inter Ethnic Cooperation." American Political Science Review, 90: 715-729.

[23] Ferejohn, J. 1986. "Incumbent Performance and Electoral Control." Public Choice, 50: $5-26$.

[24] Fudenberg, D. And Tirole, J. 1991. Game Theory. Cambridge, MA: MiT Press. 
[25] Gavazza, A. And Lizzeri, A. 2005. "Transparency and Economic Policy." Typescript. NYU.

[26] Glaeser, E. 2005. "The Political Economy of Hatred." Quarterly Journal of Economics, 120: 45-86.

[27] Harden, B. 1990. Africa: Dispatches from a Fragile Continent. New York: Norton.

[28] Herbst, J. 2000. States and Power in Africa. Princeton, NJ: Princeton University Press.

[29] Horowitz, D. 1985. Ethnic Groups in Conflict. Berkeley: University of California Press.

[30] Jackson, R. And Rosberg, C. 1982. Personal Rule in Black Africa. Berkeley: University of California Press.

[31] Lemarchand, R. 1996. Burundi: Ethnic Conflict and Genocide. New York, NY: Cambridge University Press

[32] Mbaku, J.M. 2000. Bureaucratic and Political Corruption in Africa. Malabar, Fla: Krieger Publishing Company

[33] Migdal, J. 1988. Strong Societies and Weak States. Princeton, NJ: Princeton University Press

[34] Miguel, E. And Gugerty, M. 2005. "Ethnic Diversity, Social Sanctions and Public Goods in Kenya." Journal of Public Economics, 89: 2325-2368.

[35] Posner, D. 2005. Institutions and Ethnic Politics in Africa. New York: Cambridge University Press

[36] Prunier, G. 1995. The Rwanda Crisis: History of a Genocide. New York, NY: Columbia University Press. 
[37] Robinson, J. And Verdier, T. 2002. "The Political Economy of Clientelism." CEPR Discussion Paper no. 3205.

[38] Robinson, J. and Torvik, R. 2005. "White Elephants." Journal of Public Economics, 89: 197-210.

[39] Throup, D. And Hornsby, C. 1998. Multi-Party Politics in Kenya. Athens, Oh: Ohio University Press.

[40] Van de Walle, N. 2001. The Politics of Permanent Crisis, 1979-1999. Cambridge University Press.

[41] Wa Wamwere, K. 2003. Negative ethnicity: from bias to genocide. New York: Seven Stories Press 


\section{Appendix}

\subsection{Proof to Lemma 1}

First, I associate to the constraints in program (8) the Lagrange multipliers $\lambda, \nu, \mu$ and $\rho$, respectively. The first order conditions of this program yield:

$$
\begin{aligned}
\pi^{A}+\lambda-\nu-\mu & =0 \\
1-\pi^{A}-\lambda+\nu & =0 \\
-\pi^{A}+\mu R^{\prime}\left(\eta^{A A}\right) & =0 \\
-\left(1-\pi^{A}\right)+\rho & =0
\end{aligned}
$$

From (21) it is obvious that $\eta^{A B}=0$. From (18) and (19) and the fact that $\lambda$ and $\nu$ cannot both be strictly positive at the same time we learn that $\nu=0, \lambda=1-\pi^{A}$ and $\mu=1 . \nu=0$ and $\lambda>0$ imply that the second restriction is not saturated. These values for the Lagrange multipliers directly imply the result in Lemma 1.

\subsection{Proof to Proposition 1}

First note that a potential $L^{B}$ will solve and equivalent program to (8) that has the following solution:

$$
\begin{aligned}
\eta^{B A} & =0 \\
R^{\prime}\left(\eta^{B B}\right) & =1-\pi^{A} \\
\tau^{B b} & =\Phi^{B}+R\left(\eta^{B B}\right) \\
\tau^{B a} & =\theta^{A}+\Phi^{B}+R\left(\eta^{B B}\right)
\end{aligned}
$$

Denote the mapping from expectations to current play $\Gamma\left(\Phi^{A}, \Phi^{B}\right)=\left(\tau^{A a}, \tau^{A b}, \tau^{B a}, \tau^{B b}\right)$, given by (10), (11), (22) and (23). Note that since constraint (7) is respected, groups 
always support their leaders. As a consequence, in equilibrium the continuation values for a citizen $A$ can be expressed as:

$$
\begin{aligned}
V^{A}(A) & =\omega^{a}-\tau^{A a}+R\left(\eta^{A A}\right)+\delta \bar{\gamma}^{A} V^{A}(A)+\delta\left(1-\bar{\gamma}^{A}\right) V^{A}(B) \\
V^{A}(B) & =\omega^{a}-\tau^{B a}+R\left(\eta^{B A}\right)+\delta \bar{\gamma}^{B} V^{A}(B)+\delta\left(1-\bar{\gamma}^{B}\right) V^{A}(A)
\end{aligned}
$$

Solving these equations for $V^{A}(A)-V^{A}(B)$ and substituting the resulting expression in (7), the no-subversion constraint can be written in terms of the equilibrium value of policy:

$$
\tau^{A a}-R\left(Z^{A A}\right) \leq \frac{\delta\left(\bar{\gamma}^{A}-\underline{\gamma}^{A}\right)}{1+\delta\left(1-\bar{\gamma}^{A}-\bar{\gamma}^{B}\right)}\left[\tilde{\tau}^{B a}-R\left(\tilde{\eta}^{B A}\right)-\tilde{\tau}^{A a}+R\left(\tilde{\eta}^{A A}\right)\right]
$$

Where the superscript $\sim$ denotes equilibrium values. Therefore, in terms of policy, $\Phi^{A}=\frac{\delta\left(\bar{\gamma}^{A}-\underline{\gamma}^{A}\right)}{1+\delta\left(1-\bar{\gamma}^{A}-\bar{\gamma}^{B}\right)}\left[\tilde{\tau}^{B a}-R\left(\tilde{\eta}^{B A}\right)-\tilde{\tau}^{A a}+R\left(\tilde{\eta}^{A A}\right)\right]$. This expression for $\Phi^{A}$ (and the symmetric definition of $\Phi^{B}$ ) provides a mapping from actual play to consistent expectations $\Omega\left(\tau^{A a}, \tau^{A b}, \tau^{B a}, \tau^{B b}\right)=\left(\Phi^{C A}, \Phi^{C B}\right)$. The equilibrium posits the requirement that these expectations be consistent with future play. In this context this reduces to finding a fixed point of the mapping that relates expectations to themselves: $\Omega\left(\Gamma\left(\Phi^{A}, \Phi^{B}\right)\right)=$ $\left(\Phi^{C A}, \Phi^{C B}\right)$. Explicitly, this mapping is the following:

$$
\begin{aligned}
\Phi^{C A} & =\frac{\delta\left(\bar{\gamma}^{A}-\underline{\gamma}^{A}\right)}{1+\delta\left(1-\bar{\gamma}^{A}-\bar{\gamma}^{B}\right)}\left[\theta^{A}+\Phi^{B}+R\left(\eta^{B B}\right)-\Phi^{A}-R\left(\eta^{A A}\right)+R\left(\eta^{A A}\right)\right] \\
\Phi^{C B} & =\frac{\delta\left(\bar{\gamma}^{B}-\underline{\gamma}^{B}\right)}{1+\delta\left(1-\bar{\gamma}^{A}-\bar{\gamma}^{B}\right)}\left[\theta^{B}+\Phi^{A}+R\left(\eta^{A A}\right)-\Phi^{B}-R\left(\eta^{B B}\right)+R\left(\eta^{B B}\right)\right]
\end{aligned}
$$

For simplicity denote $\Psi^{i}=\frac{\delta\left(\bar{\gamma}^{i}-\underline{\gamma}^{i}\right)}{1+\delta\left(1-\bar{\gamma}^{A}-\bar{\gamma}^{B}\right)}$. Solving this system for the fixed point $\left(\Phi^{A}, \Phi^{B}\right)=$ $\left(\Phi^{C A}, \Phi^{C B}\right)$ yields:

$$
\begin{aligned}
\Phi^{A} & =\frac{\Psi^{A}\left(1+\Psi^{B}\right)\left(\theta^{A}+R\left(\eta^{B B}\right)\right)+\Psi^{A} \Psi^{B}\left(\theta^{B}+R\left(\eta^{A A}\right)\right)}{1+\Psi^{A}+\Psi^{B}} \\
\Phi^{B} & =\frac{\Psi^{B}\left(1+\Psi^{A}\right)\left(\theta^{B}+R\left(\eta^{A A}\right)\right)+\Psi^{A} \Psi^{B}\left(\theta^{A}+R\left(\eta^{B B}\right)\right)}{1+\Psi^{A}+\Psi^{B}}
\end{aligned}
$$


Since there is a single fixed point, uniqueness of MPE is shown. These values for $\Phi^{A}$ and $\Phi^{B}$, together with Lemma 1 establish the proposition.

\subsection{Proof to Proposition 2}

Denote by $V_{M P E}^{A}(A)$ the lifetime payoff for citizen $A$ in the MPE starting at state $A$. Define in analogous terms $V_{M P E}^{A}(B), V_{M P E}^{B}(A)$ and $V_{M P E}^{B}(B)$. Denote by $V_{F B}^{A}=\frac{1}{1-\delta}\left[\omega^{A}-\eta^{*}+R\left(\eta^{*}\right)\right]$ and $V_{F B}^{B}=\frac{1}{1-\delta}\left[\omega^{B}-\eta^{*}+R\left(\eta^{*}\right)\right]$. These are the first best payoffs.

From the point of view of the ruler, assuming that his supporters play the equilibrium strategy, he obtains 0 in any possible deviation and in equilibrium. Hence, proposing $P^{*}$ is a best response.

The ruler can try to break the collusion of the citizens by offering the best possible payoff to his supporters and hope that they will accept it. Given constraints (5) and (6) and the stragies postulated, the best payoff to his supporters is (assume without loss of generality that $\left.S_{t}=A\right)$ :

$$
V_{D E V}^{A}(A)=\omega^{A}-\pi \eta_{*}^{A}+(1-\pi) \theta^{B}+R\left(\eta_{*}^{A}\right)+\delta \bar{\gamma}^{A} V_{M P E}^{A}(A)+\delta\left(1-\bar{\gamma}^{A}\right) V_{M P E}^{A}(B)
$$

The supporters will support him only if $V_{D E V}^{A}(A) \geq V_{F B}^{A}$. However,

$$
\begin{aligned}
V_{F B}^{A}-V_{D E V}^{A}(A)= & {\left[R\left(\eta^{*}\right)-R\left(\eta_{*}^{A}\right)-(1-\pi) \theta^{B}+\pi \eta_{*}^{A}-\eta^{*}\right]+} \\
& +\frac{\delta}{1-\delta}\left[R\left(\eta^{*}\right)-\eta^{*}+\frac{\Phi^{A}\left[\bar{\gamma}^{A}+\delta\left(1-\bar{\gamma}^{A}-\bar{\gamma}^{B}\right)\right]+\left[\Phi^{B}+\theta^{A}+R\left(\eta_{*}^{B}\right)\right]\left(1-\bar{\gamma}^{A}\right)}{1+\delta\left(1-\bar{\gamma}^{A}-\bar{\gamma}^{B}\right)}\right]
\end{aligned}
$$

Now, the first additive term is negative. However, the second additive term is strictly positive. Clearly, for $\delta$ close enough to 1 the difference is positive.

Hence there is no current payoff that can compensate the supporting group from breaking the equilibrium and falling into the MPE. Since the MPE equilibrium is selfsustainable as a punishment strategy, the proposed strategy profile is a SPE that supports first best for the citizens. 


\subsection{Comparative Statics}

The expressions for the comparative statics of $\Phi^{A}$ with respect to the institutional parameters depend on the following partial derivatives:

$$
\begin{aligned}
& \frac{\partial \Phi^{A}}{\partial \Psi^{A}}=\frac{\left(1+\Psi^{B}\right)^{2}\left(\theta^{A}+R\left(\eta^{B B}\right)\right)+\left(1+\Psi^{B}\right) \Psi^{B}\left(\theta^{B}+R\left(\eta^{A A}\right)\right)}{\left[1+\Psi^{A}+\Psi^{B}\right]^{2}}>0 \\
& \frac{\partial \Phi^{A}}{\partial \Psi^{B}}=\frac{\Psi^{A}\left(\theta^{A}+R\left(\eta^{B B}\right)\right)+\left(1+\Psi^{A}\right) \Psi^{A}\left(\theta^{B}+R\left(\eta^{A A}\right)\right)}{\left[1+\Psi^{A}+\Psi^{B}\right]^{2}}>0 \\
& \frac{\partial \Psi^{A}}{\partial \bar{\gamma}^{A}}=\frac{\delta\left(1-\delta \bar{\gamma}^{B}\right)+\delta^{2}\left(1-\underline{\gamma}^{A}\right)}{\left[1+\delta\left(1-\bar{\gamma}^{A}-\bar{\gamma}^{B}\right)\right]^{2}}>0 \\
& \frac{\partial \Psi^{A}}{\partial \underline{\gamma}^{A}}=-\frac{\delta}{1+\delta\left(1-\bar{\gamma}^{A}-\bar{\gamma}^{B}\right)}<0 \\
& \frac{\partial \Psi^{A}}{\partial \bar{\gamma}^{B}}=\frac{\delta^{2}\left(\bar{\gamma}^{A}-\underline{\gamma}^{A}\right)}{\left[1+\delta\left(1-\bar{\gamma}^{A}-\bar{\gamma}^{B}\right)\right]^{2}}>0 \\
& \frac{\partial \Psi^{A}}{\partial \underline{\gamma}^{B}}=0 \\
& \frac{\partial \Psi^{B}}{\partial \bar{\gamma}^{A}}=\frac{\delta^{2}\left(\bar{\gamma}^{B}-\underline{\gamma}^{B}\right)}{\left[1+\delta\left(1-\bar{\gamma}^{A}-\bar{\gamma}^{B}\right)\right]^{2}}>0 \\
& \frac{\partial \Psi^{B}}{\partial \underline{\gamma}^{A}}=0 \\
& \frac{\partial \Psi^{B}}{\partial \bar{\gamma}^{B}}=\frac{\delta\left(1-\delta \bar{\gamma}^{A}\right)+\delta^{2}\left(1-\underline{\gamma}^{B}\right)}{\left[1+\delta\left(1-\bar{\gamma}^{A}-\bar{\gamma}^{B}\right)\right]^{2}}>0 \\
& \frac{\partial \Psi^{A}}{\partial \underline{\gamma}^{A}}=-\frac{\delta}{1+\delta\left(1-\bar{\gamma}^{A}-\bar{\gamma}^{B}\right)}<0
\end{aligned}
$$

